\title{
O BRANDING E A METODOLOGIA DE SISTEMAS DE IDENTIDADE VISUAL
}

\author{
BRANDING AND METHODOLOGY OF VISUAL IDENTITY SYSTEMS
}

\author{
Sandra Ribeiro Cameira \\ Universidade de São Paulo \\ srcameira@hotmail.com
}

\section{RESUMO}

O planejamento estratégico de branding começou a ser praticado nos escritórios de design brasileiros a partir de meados da década de 1990, e representou uma importante evolução para o design gráfico brasileiro tanto do ponto de vista metodológico como mercadológico. Esse novo estado da arte no campo do design, motivou a realização de uma pesquisa qualitativa em um Programa de pós-graduação, com o objetivo de compreender esse movimento, documentar as consequências práticas deste processo, e contribuir na disseminação de novos conceitos e fundamentos teóricos sobre branding, que possam conduzir os profissionais que atuam na área de identidade visual a uma atuação mais estratégica e especializada. A pesquisa teve, ainda, o intuito de enriquecer a bibliografia sobre as relações entre marca, identidade visual, identidade corporativa e branding na concepção, construção e gestão de marcas corporativas no campo do design gráfico.

Palavras-chave: marcas, identidade visual, metodologia, branding.

\section{ABSTRACT}

The strategic planning of branding started to be used in the Brazilian design offices since the mid nineties and represented an important evolution for graphic design in Brazil both in methodological and marketing sense. This new state of art in 
the design field motivated the development of a qualitative research aiming to understand this movement, document the practical consequences of the process, and contribute to the dissemination of new concepts and theoretical fundamentals of branding, which may drive the professionals that work in the visual identity industry towards a more strategic and specialized performance. Moreover, there was also the idea of enriching the bibliography about the relationships between brand, visual identity, corporate identity and branding in its conception, construction and management of corporate brands in the graphic design field.

Key words: brands, visual identity, methodology, branding. 


\section{INTRODUÇÃO}

O planejamento de branding passou a ser realizado pelos escritórios de design brasileiros em projetos de construção de identidades de marcas a partir de meados da década de 1990. Até então, os designers não se envolviam nos processos estratégicos de construção e gestão das marcas e atuavam, essencialmente, no desenvolvimento do seu universo visual. Por esse motivo, esse trabalho era denominado como "Projeto de Identidade Visual".

Segundo o administrador de empresas e consultor de branding José Roberto Martins (2006), "branding é o conjunto de ações ligadas à administração das marcas". Todos os autores consultados concordam, em essência, que hoje branding é um sistema de gerenciamento das marcas orientado pela significância e influência que as marcas podem ter na vida das pessoas, objetivando a geração de valor para os seus públicos de interesse.

O branding começou a ser utilizado pelas empresas, tanto na Europa como nos Estados Unidos, em meados do século XX, como ferramenta de gestão de marcas de produtos de consumo. A Procter\&Gamble é reconhecida por ter sido a primeira empresa a criar, em 1931, times de gerenciamento de marcas que tinham como principal função coordenar o programa de marketing dos produtos de forma integrada à venda e à fabricação.

Com o passar do tempo, as marcas aumentaram a abrangência de sua atuação e assumiram um novo papel no cotidiano dos indivíduos, constituindo-se em indicadores da identidade de seus públicos, e este cenário contribuiu para reforçar a importância do branding como sistema de gestão das marcas.

O tema da inclusão do branding nos projetos de identidades visuais corporativas foi escolhido para a minha pesquisa, porque esse processo representou uma importante mudança para o campo do design gráfico, tanto do ponto de vista metodológico como mercadológico. 
Nesse contexto, esta pesquisa buscou investigar até que ponto a inclusão de uma nova disciplina (não originária do universo do design, mas das escolas de administração de empresas), no processo de concepção e criação de uma marca, ocasionou uma mudança de paradigma na metodologia de projetos de identidade visual em relação à metodologia anteriormente adotada - primordialmente, da década de 1960 até meados dos anos 1990 - ou se foi um "desenvolvimento natural", complementar à prática até então seguida pelos designers, em função dos rumos do mercado, da expansão da atuação do marketing ou ainda de uma nova visão sobre o significado da marca.

A investigação também procurou entender como ocorreu a integração entre as duas disciplinas - design e branding - nos escritórios de design pesquisados e as consequências práticas desse processo.

A questão central da pesquisa indagou: "Teria havido uma mudança de paradigma na metodologia dos projetos de identidade visual com a inclusão do branding em relação aos projetos executados nas décadas anteriores?"

Essa questão conduziu a outras perguntas para o entendimento da forma pela qual as duas disciplinas - design e branding - se integraram e as consequências práticas desse processo:

- $\quad$ O que motivou os escritórios de design a incorporarem a prática do branding em seus projetos: foi um movimento recíproco entre os profissionais de design e de marketing - ou clientes -, ou houve uma demanda inicial de uma das partes?

- Sobre quais conceitos teóricos de branding os designers fundamentam sua nova atuação: sobre as teorias clássicas de administração e marketing ou sobre uma metodologia própria do escritório?

- $\quad$ A inclusão de equipes multidisciplinares na rotina do projeto proporcionou uma nova forma de elaboração do pensamento do designer na busca da solução ideal para construção de uma marca?

- $\quad$ Como deve ser o perfil do designer que atua em um escritório que inclui a criação do plano de branding em seus projetos? Quais novas disciplinas ele deve dominar?

- De que maneira os profissionais dos escritórios de design adquiriram formação teórica e capacitação para dominar esses novos conceitos e ferramentas?

- A inclusão do branding na metodologia tornou-se um diferencial competitivo do escritório?

Ao se documentar e evidenciar esse novo estado da arte no campo do design, em projetos de identidade visual corporativa, a pesquisa contribuiu para ampliar o 
conhecimento sobre a trajetória da atividade profissional e a evolução da metodologia empregada pelos principais escritórios de design especializados nesse segmento nos últimos 40 anos. Também favoreceu a atualização profissional no segmento, enriquecendo a bibliografia especializada sobre design associado ao branding e introduzindo novos conceitos e fundamentos teóricos sobre branding no repertório conceitual do designer, para poder conduzi-lo a uma abordagem mais estratégica na criação, construção e gestão de marcas corporativas, que acompanhe a tendência do mercado local e mundial de design.

O embasamento teórico foi justificado segundo autores especialistas em semiótica das marcas, e metodologias de projetos de design de identidades corporativas, dentre os quais destacam-se: Andrea Semprini, Maria Clotilde Perez, Norberto Chaves, Joan Costa, Wally Olins. Em um capítulo específico, a pesquisa expõe as principais definições e contextos inerentes aos universos do design, das marcas e do branding para esclarecer e pontuar a fundamentação teórica de toda a investigação.

Não foi objetivo da pesquisa discutir a cronologia dos termos e conceitos relacionados à marca, identidade visual, identidade corporativa e branding, mas é importante esclarecer que, ao longo da investigação, tornou-se evidente uma mudança na concepção de alguns desses conceitos, se compararmos as definições de marca enunciadas por diversos autores até o início dos anos 1990 e após meados desta mesma década. Percebemos concepções bastante distintas, certamente associadas a uma mudança na própria concepção de marca, decorrente da evolução do seu papel nas sociedades.

O conceito de branding também evoluiu. Alexandre Wollner, assim como outros designers da geração pioneira, afirmaram que faziam branding desde a década de 1960 e 1970, ao desenvolverem projetos de identidade visual. Para eles, o "fazer branding" significa olhar a marca de uma perspectiva mais ampla, observando todas as suas manifestações visuais e expressões diante dos públicos com os quais ela se relaciona. Essa definição não pode ser considerada equivocada, porém é incompleta diante da concepção de branding atualmente entendida pelos profissionais que atuam nesse segmento. 


\section{A INVESTIGAÇÃO: EVOLUÇÃO OU MUDANÇA DE PARADIGMA?}

\subsection{Metodologias para o design de identidades visuais}

No centro desta pesquisa coloca-se a questão da metodologia empregada pelos designers na construção de identidades visuais corporativas. Nesse sentido, destacamse os autores que dissertaram sobre o processo metodológico do campo do design de forma geral - Gustavo Amarante Bonfim e Bernd Löbach - e, mais especificamente, a metodologia defendida por Marco Antônio Amaral Rezende (1979) e Alina Wheeler (2008) no que diz respeito à metodologia para construção de marcas.

Do ponto de vista de vista da metodologia, foram comparadas as metodologias apresentadas por REZENDE (1979, p.26-30) e WHEELER (2008, p.80-81), em que os autores resumiram as etapas do trabalho de construção da identidade da marca. É correto afirmar que a inclusão do planejamento de branding determinou o acréscimo de novas etapas em duas fases do processo: no início do trabalho, a etapa de diagnóstico desdobrou-se na investigação e na criação da estratégia, e na etapa final, foi acrescentada a etapa de gestão dos ativos da marca. Os gráficos abaixo apresentam esquematicamente as etapas que compõem as metodologias propostas pelos dois autores, em cada época:

Metodologia segundo Rezende (1979)

\begin{tabular}{|l|l|l|l|l|}
\hline \multicolumn{1}{|c|}{ Plano diretor } & \multicolumn{2}{|c|}{ Criação linguagem visual } & $\begin{array}{c}\text { Mensagens visuais } \\
+ \text { implantação }\end{array}$ & \multicolumn{1}{c|}{$\begin{array}{c}\text { Normatização e } \\
\text { padronização }\end{array}$} \\
\hline Entrevistas & Nome & Marca & Formulários & $\begin{array}{c}\text { Manual de identidade } \\
\text { visual }\end{array}$ \\
Pesquisa & Diretrizes & $\begin{array}{l}\text { Logotipo } \\
\text { empresarial }\end{array}$ & $\begin{array}{l}\text { Publicidade } \\
\text { Embalagens }\end{array}$ & \\
Pesquisa & Programa & Logotipo produtos & Promoção de vendas & \\
Imagem interna & & Alfabeto & Identificação externa & \\
Concorrência e & & Cores & Sinalização interna & \\
ambiente & & Assinatura & Mobiliário & \\
Análise & completa & Arquitetura & \\
Mensagens visuais & & & Stands & \\
& & & Uniformes & \\
& & & Equipamentos & \\
& & & Veículos & \\
& & & Diversos & \\
\hline
\end{tabular}

Fonte: (REZENDE, 1979, p.26-30). 
Metodologia segundo Wheeler (2008)

\begin{tabular}{|c|c|c|c|c|}
\hline $\begin{array}{l}\text { Condução da } \\
\text { Pesquisa }\end{array}$ & $\begin{array}{l}\text { Classificação da } \\
\text { Estratégia }\end{array}$ & $\begin{array}{l}\text { Design da } \\
\text { identidade }\end{array}$ & $\begin{array}{l}\text { Criação de pontos } \\
\text { de contato }\end{array}$ & Gestão ativos \\
\hline $\begin{array}{l}\text { Tornar claro: visão, } \\
\text { estratégia, metas e } \\
\text { valores } \\
\text { Pesquisar as } \\
\text { necessidades e } \\
\text { percepções dos } \\
\text { stakeholders } \\
\text { Concluir auditorias } \\
\text { sobre marketing, } \\
\text { concorrência, } \\
\text { tecnologia, jurídica } \\
\text { e linguagem }\end{array}$ & $\begin{array}{l}\text { Sintetizar o que } \\
\text { for aprendido } \\
\text { Classificar a } \\
\text { estratégia de } \\
\text { marca } \\
\text { Desenvolver uma } \\
\text { plataforma de } \\
\text { posicionamento } \\
\text { Cocriar atributos } \\
\text { de marca } \\
\text { Escrever resumo } \\
\text { de marca (brief) } \\
\text { Obter aprovação } \\
\text { Criar uma } \\
\text { estratégia de } \\
\text { nomes } \\
\text { Escrever um } \\
\text { resumo criativo }\end{array}$ & $\begin{array}{l}\text { Visualizar o futuro } \\
\text { Brainstorm da } \\
\text { grande ideia } \\
\text { Explorar as } \\
\text { aplicações } \\
\text { Finalizar a } \\
\text { arquitetura da } \\
\text { marca } \\
\text { Apresentar a } \\
\text { estratégia visual } \\
\text { Obter aprovação }\end{array}$ & $\begin{array}{l}\text { Finalizar o design } \\
\text { de identidade } \\
\text { Desenvolver } \\
\text { aparência e sentido } \\
\text { Começar a } \\
\text { proteção da marca } \\
\text { registrada } \\
\text { Priorizar e fazer o } \\
\text { design das } \\
\text { aplicações } \\
\text { Fazer o design do } \\
\text { programa } \\
\text { Aplicar a } \\
\text { arquitetura de } \\
\text { marca }\end{array}$ & $\begin{array}{l}\text { Construir } \\
\text { sinergia ao } \\
\text { redor da marca } \\
\text { Desenvolver a } \\
\text { estratégia e o } \\
\text { plano de } \\
\text { lançamento } \\
\text { Lançar primeiro } \\
\text { internamente } \\
\text { Lançar } \\
\text { externamente } \\
\text { Desenvolver } \\
\text { diretrizes de } \\
\text { padronização e } \\
\text { normatização } \\
\text { Treinar os } \\
\text { campeões de } \\
\text { marcas }\end{array}$ \\
\hline
\end{tabular}

Fonte: WHEELER, 2008, p.80-81.

Apesar de as metodologias acima terem sido declaradas em épocas distintas, Rezende e Wheeler concordam que, comumente, o processo para a criação de uma identificação institucional é composto primeiramente por uma fase de investigação e pesquisa, seguida por uma fase de execução e implementação. Entretanto, é possível observar que ao incluir o branding, o projeto passa a considerar questões de natureza mais estratégica e subjetiva, como "desenvolver uma plataforma de posicionamento da marca", "construir a sinergia ao redor da marca" e "desenvolver a estratégia e o plano de lançamento".

\subsection{Pesquisa qualitativa}

A pesquisa qualitativa foi realizada por meio de entrevistas com designers titulares dos principais escritórios de design que atuam com projetos de identidade 
visual e branding no eixo Rio de Janeiro-São Paulo, e também com diretores executivos de três consultorias de branding $^{1}$, a fim de se comparar e confrontar as metodologias utilizadas por cada empresa em seus projetos. A seleção das empresas participantes considerou como condição inicial a formação acadêmica desses profissionais e a trajetória da empresa no mercado brasileiro, no desenvolvimento de relevantes trabalhos no segmento de identidades de marca. Dentre os dois grupos, prestaram depoimento os seguintes profissionais:

a) Designers (escritórios de design): Alexandre Wollner, Ana Couto Branding \& Design, Antonio Roberto de Oliveira (Managic), Carlos Dranger, João Carlos Cauduro e Marco Antônio Rezende (Cauduro Associados), Ricardo Leite (Crama Design Estratégico), Gilberto Strunck (Dia Comunicação de Marketing), Marcelo Bicudo (Epigram), Cesar Hirata (Future Brands), Hugo Kovadloff (Gad Design), Nair de Paula Soares e Rafael Rodrigues (PVDI Design), Lincoln Seragini (Seragini Farné Guardado), Ronald Kapaz (Oz Design), Fred Gelli (Tátil Design) e Norberto Chamma (Und Corporate Design).

b) Consultorias de Branding: Laura Garcia (Interbrand), Marcos Machado (Top Brands), Ricardo Guimarães (Thymus Branding).

As entrevistas realizadas ofereceram uma perspectiva privilegiada para se olhar o campo do design de identidades de marcas com o branding inserido nesse contexto. A análise recaiu, mais especificamente, sobre a evolução histórica da incorporação dessa nova disciplina no escopo do trabalho do designer, e nas consequências práticas desse processo.

A maioria dos profissionais entrevistados percebeu, ainda na primeira metade da década de 1990, que havia a necessidade de eles se atualizarem na metodologia de construção de identidades visuais, para acompanhar uma tendência do mercado internacional. E se mobilizaram, por diferentes meios, para se capacitarem diante do desafio de incorporar o branding ao processo metodológico do design.

Já do ponto de vista de mercado, todos os entrevistados concordaram que o projeto de construção de identidade de marca com escopo ampliado pelo branding, adquiriu um caráter mais estratégico e, por isso, é bem mais valorizado pelo mercado.

\footnotetext{
${ }^{1}$ Das três consultorias de branding entrevistadas, apenas a Interbrand possui equipe interna composta por
} 
Este fator propiciou um aumento exponencial nos honorários praticados nos projetos. O trabalho de branding passou a ser um importante fator de diferenciação, evidenciando os escritórios habilitados a oferecer a especialidade.

\subsection{Análise de casos}

Em seguida às entrevistas, foram selecionados para análise, como objetos de estudo comparado, quatro projetos de construção de identidades visuais realizados pelos profissionais de alguns dos escritórios entrevistados para empresas brasileiras, sendo: dois projetos que não incluíram o trabalho de branding e dois projetos que incluíram - considerando-se que o branding se define a partir do estabelecimento das diretrizes estratégicas para construção das marcas em questão, objetivando a criação de valor e o fortalecimento delas.

Pertencem ao primeiro grupo projetos de identidade visual desenvolvidos por dois escritórios de design paulistanos, a saber: Indústrias Villares, por Cauduro/Martino (1967); e Rodovia NovaDutra, por Und Design Corporate (1997).
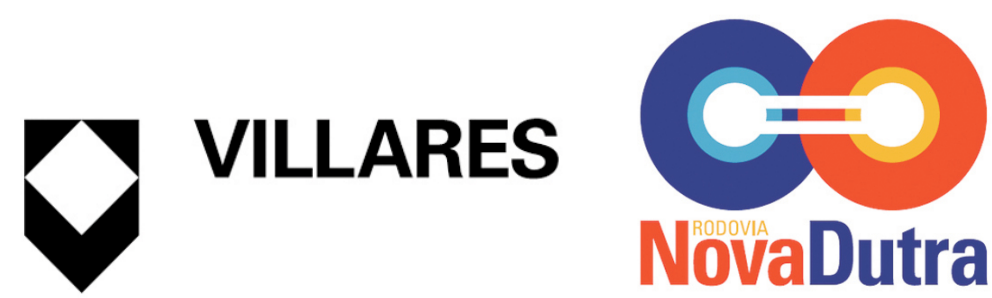

Fonte: Cauduro Associados / Und Corporate Design

No segundo grupo - projetos que incluíram o trabalho de branding - foram analisados dois redesenhos de identidades de marcas brasileiras com atuação multinacional: a Vale (2007), pela Cauduro Associados; e a Penalty (2008), por Oz Design - ambos os escritórios também situados em São Paulo. 


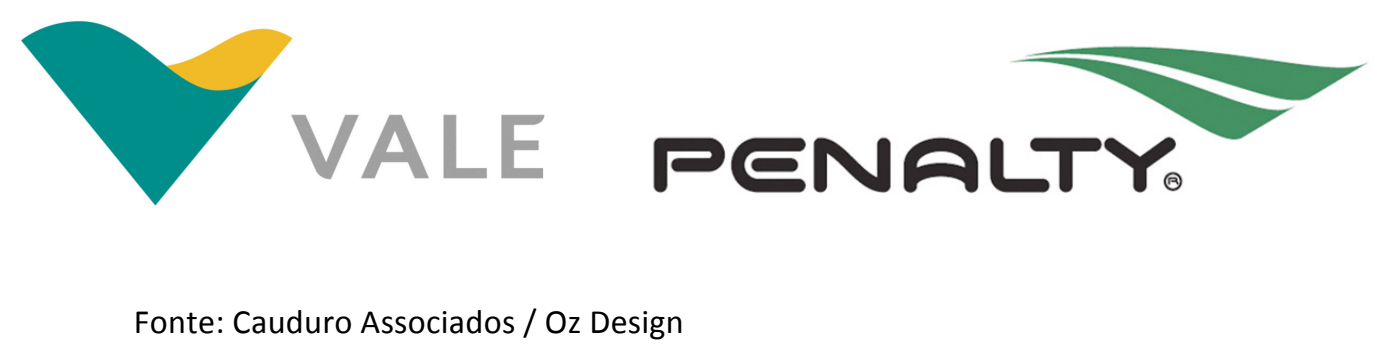

Fonte: Cauduro Associados / Oz Design

O método utilizado no tratamento dos dados foi a análise comparativa entre os projetos. Primeiramente, eles foram examinados em duplas - por meio de uma análise sincrônica - entre aqueles que não incluíram o trabalho de branding e os que incluíram. Depois foi feita a análise diacrônica entre os quatro projetos, para se identificar, nos dois contextos, em quais particularidades eles se diferenciavam ou se assemelhavam e se houve a introdução de novos elementos nos materiais apresentados ao cliente em função da metodologia utilizada.

Outro aspecto investigado nos estudos de caso diz respeito à "entrega" do projeto propriamente dita. Ou seja, foram analisadas e comparadas - em sua forma e conteúdo - os materiais entregues aos clientes nos quatro projetos. Observou-se que a entrega feita nos projetos de construção de marca com branding, é mais completa e consistente, pois fornece ao cliente um conjunto de conceitos e atributos relacionados aos significados que a marca possui, guarnecidos também pela estruturação de suas manifestações visuais e verbais, de forma integrada e estruturada. O sistema de identidade visual passa a ser um dos componentes da identidade da marca, o qual, anteriormente, era o projeto por excelência.

A inclusão de um novo escopo das etapas de projeto, mais abrangente, exigiu uma apresentação didática e clara do projeto e de seus fundamentos. As pranchas e manuais de identidade visual anteriormente apresentados ao final do trabalho compõem, hoje, apenas uma parte da entrega do projeto de construção da marca, cuja peça mais importante e estratégica entregue ao cliente é o Brandbook ou o "Livro da marca".

Cabe destacar a questão da evolução das ferramentas de trabalho utilizadas pelos designers no dia a dia do projeto, as quais propiciaram um aperfeiçoamento nos 
materiais apresentados aos clientes. A abertura do mercado de tecnologia no início da década de 1990 popularizou o uso dos softwares gráficos entre os designers e proporcionam maior agilidade e precisão, tanto na criação dos desenhos de projeto (layouts), como na produção dos originais para reprodução (artes-finais) dos materiais desenvolvidos. Nesse contexto, pode-se afirmar que todas as etapas do trabalho de design que, de algum modo, estejam vinculadas a estas ferramentas, sofreram uma evolução decorrente do uso da tecnologia, independentemente da inclusão do branding.

A análise comparativa pretendeu-se apurar se a incorporação do branding ao projeto representou uma completa mudança de paradigma na metodologia de construção de marcas ou um desenvolvimento (ou evolução) em relação ao método anterior.

Para se expor mais didaticamente as mudanças identificadas nessa análise, foram descritas as diferenças entre aquilo que se manteve igual, o que mudou ou evoluiu e o que é novo (ou um novo paradigma), em todo o processo de construção de uma identidade de marca.

Primeiramente, foram classificadas as mudanças na metodologia adotada e no escopo do trabalho. Em seguida, as mudanças no campo profissional, ou seja, na estrutura e forma de atuação do escritório no projeto. Foram analisados e comparados a metodologia e escopo do projeto e a estrutura e forma de atuação.

Para facilitar a visualização simultânea de todas as questões e conclusões oriundas da análise comparativa da pesquisa, apresentamos, a seguir, o quadro em formato de matriz.

\begin{tabular}{|c|c|c|c|}
\hline \multirow{5}{*}{ 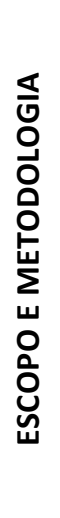 } & & \multicolumn{2}{|l|}{ CONCLUSÃO } \\
\hline & $\begin{array}{l}\text { Conceitos e } \\
\text { fundamentos para } \\
\text { embasar o projeto }\end{array}$ & [Evoluiu] & $\begin{array}{l}\text { O branding trouxe novos conceitos para reforçar a } \\
\text { dimensão simbólica, emocional e de negócio das } \\
\text { marcas. }\end{array}$ \\
\hline & $\begin{array}{l}\text { Estudo do mercado de } \\
\text { atuação }\end{array}$ & [Evoluiu] & $\begin{array}{l}\text { Novas ferramentas de pesquisa e benchmarking: } \\
\text { melhor visão de todos os players do mercado. }\end{array}$ \\
\hline & $\begin{array}{l}\text { Definição da estratégia } \\
\text { e posicionamento }\end{array}$ & [É algo novo] & $\begin{array}{l}\text { A estratégia determina os atributos/diferenciais } \\
\text { da marca. O trabalho adquire visão de gestão e de } \\
\text { negócio. }\end{array}$ \\
\hline & Definição de nome & [Evoluiu] & $\begin{array}{l}\text { Década de 1970: Décio Pignatari e Wollner. } \\
\text { Hoje: trabalho mais profissional e valorizado. }\end{array}$ \\
\hline
\end{tabular}




\begin{tabular}{|l|l|ll|}
\hline Design da marca & [Evoluiu] & $\begin{array}{l}\text { O branding pode orientar a criação de um } \\
\text { desenho mais ajustado e coerente com o } \\
\text { posicionamento da marca. }\end{array}$ \\
\cline { 2 - 4 } & $\begin{array}{l}\text { Sistema visual (cores, } \\
\text { tipografia e demais } \\
\text { elementos) }\end{array}$ & [Não mudou] & \\
\hline $\begin{array}{l}\text { Universo verbal / Tom } \\
\text { de voz / Mensagens } \\
\text { chave }\end{array}$ & [É algo novo] & $\begin{array}{l}\text { O projeto define e orienta a linguagem de } \\
\text { expressão verbal da marca, reforçando seu "jeito } \\
\text { de ser". }\end{array}$ \\
\hline $\begin{array}{l}\text { Definição de estilo } \\
\text { visual + linguagem de } \\
\text { fotos e ilustrações }\end{array}$ & [É algo novo] & $\begin{array}{l}\text { O projeto define e orienta o uso de imagens } \\
\text { (fotos/ilustrações) reforçando o "jeito de ser" da } \\
\text { marca. }\end{array}$ \\
\hline $\begin{array}{l}\text { Extensões do projeto e } \\
\text { aplicações da } \\
\text { identidade visual }\end{array}$ & [Evoluiu] & $\begin{array}{l}\text { A tecnologia expandiu a quantidade de itens } \\
\text { apresentados e agilizou o desenvolvimento desses } \\
\text { elementos. }\end{array}$ \\
\cline { 2 - 4 } & $\begin{array}{l}\text { Ferramentas de gestão } \\
\text { da marca }\end{array}$ & [Evoluiu] & $\begin{array}{l}\text { O branding exige e propicia maior integração } \\
\text { entre cliente e designer, e este propaga os } \\
\text { conceitos da marca. }\end{array}$ \\
\hline
\end{tabular}

Fonte: elaborado pelo autor, com base na pesquisa realizada.

\begin{tabular}{|c|c|c|c|}
\hline \multirow{5}{*}{ 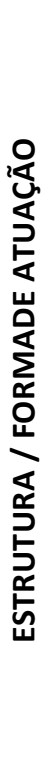 } & & \multicolumn{2}{|c|}{ CONCLUSÃO } \\
\hline & $\begin{array}{l}\text { Apresentação e } \\
\text { execução dos layouts }\end{array}$ & [Evoluiu] & $\begin{array}{l}\text { A tecnologia agilizou a produção de apresentações, } \\
\text { aperfeiçoou os layouts e a representação visual das } \\
\text { peças. Brandbooks e apresentações mais lúdicas e } \\
\text { aparentes. }\end{array}$ \\
\hline & $\begin{array}{l}\text { Tempo de execução do } \\
\text { projeto }\end{array}$ & [Mudou] & $\begin{array}{l}\text { Cronograma aumentado pela incorporação de novas } \\
\text { tarefas da etapa de branding. Por outro lado, os } \\
\text { softwares reduziram o tempo de execução do } \\
\text { trabalho de design. }\end{array}$ \\
\hline & $\begin{array}{l}\text { Equipe envolvida no } \\
\text { projeto }\end{array}$ & [Evoluiu] & $\begin{array}{l}\text { Equipes multidisciplinares são formadas, para } \\
\text { contribuir na etapa de branding para definição da } \\
\text { estratégia e de conceitos para o projeto. }\end{array}$ \\
\hline & Honorários praticados & [Evoluiu] & $\begin{array}{l}\text { Maior complexidade devido à criação da estratégia } \\
\text { de branding; Maior valor agregado, que possibilita a } \\
\text { prática de honorários mais elevados. }\end{array}$ \\
\hline
\end{tabular}

Fonte: elaborado pelo autor, com base na pesquisa realizada.

\section{CONCLUSÃO}

O projeto de branding foi introduzido como uma prática efetiva nos principais escritórios de design brasileiros especializados na construção de identidades de marca a partir de meados da década de 1990 e se consolidou a partir dos anos 2000. 
O cenário contemporâneo, comandado pela intensificação da globalização, o crescimento do mercado como um todo (mais produtos e marcas disputando a atenção dos consumidores), o aumento do consumo, e a tecnologia acessível, exigiam uma nova postura das empresas em relação à gestão de seu patrimônio e, principalmente, de suas marcas. E um importante recurso veio de exemplos de adoção do branding no exterior.

A partir dos primeiros anos da década de 1990, os designers brasileiros perceberam que esse novo cenário demandava que eles se mobilizassem a fim de se capacitarem diante do desafio de incorporar o branding ao processo do design.

A metodologia para criação de uma marca gráfica, em linhas gerais, é a mesma que se praticava desde a década de 1960. Já ao se analisar o processo de construção de "marca" pode-se concluir que houve um desenvolvimento e um aumento no grau de complexidade dos projetos a partir da introdução do branding. Todos os profissionais entrevistados assumiram que seus escritórios adotam uma metodologia própria, resultante da sua experiência acumulada, somada a novos conhecimentos teóricos de branding obtidos posteriormente.

A determinação da estratégia pode orientar e inspirar a criação de um signo mais coerente com o posicionamento da marca, colaborando também para a construção de uma estética simbólica mais completa que atinja os pontos de contato da marca e seus públicos mais importantes.

Em relação aos honorários cobrados pelo projeto de construção de marca, todos os entrevistados concordaram que houve uma completa mudança de paradigma. A nova oferta de serviço, com escopo ampliado, aumentou o tempo do trabalho e o número de profissionais especializados envolvidos. Por ser bem mais estratégica, a atividade é mais valorizada pelo mercado e tais fatores, consequentemente, elevaram exponencialmente os honorários praticados, tornandose, essa estratégia, um diferencial competitivo do escritório, não somente por sua visibilidade de mercado, como pela própria estabilidade do negócio.

No entanto, a especialização em branding não é uma condição sine quae non para o designer atuar no segmento de identidades de marca. Ainda existe uma demanda para criação de sistemas de identidade visual para pequenas e 
microempresas, comércios locais, e profissionais liberais.

Escritórios de design de menor porte não capacitados em branding podem, ainda, atuar projetando identidades visuais em parceria ou prestando serviços de design para as consultorias de branding que terceirizam essa etapa do projeto. Para tanto, é necessário que o designer tenha o conhecimento mínimo sobre branding para atuar em coerência com os princípios da consultoria contratante.

Assim, a pesquisa concluiu que o principal paradigma modificado é a noção de construção da identidade de marca que é expressa pela inclusão de novas etapas, que implicam o aumento da complexidade do projeto e, consequentemente, nos honorários praticados.

Algumas investigações podem surgir como desdobramentos desta pesquisa, as quais poderiam ter as seguintes questões centrais não contempladas:

- $\quad$ Seria possível o desenvolvimento de um projeto de branding voltado para pequenas empresas?

- Quais as diferenças, do ponto de vista metodológico, entre um projeto de branding no segmento cultural e o tradicional projeto de branding corporativo?

- $\quad$ E como esta nova segmentação pode ampliar as oportunidades de atuação no campo do design?

Espero que o olhar desta pesquisa para a inclusão do branding no contexto do design de identidades de marca - um paradigma relativamente recente neste campo profissional - contribua para diversificar o cenário atual do mercado do design gráfico brasileiro e abra novas perspectivas de trabalho a todos os estudantes de design e/ou profissionais que atuam nesta especialidade, dos já experientes aos novos ingressantes.

\section{REFERÊNCIAS}

$A B C$ da $A D G$. Glossário de termos e verbetes utilizados em design gráfico. São Paulo: ADG, 2000.

ABDI, MASP. Panorama da identidade visual. Publicado no seminário Panorama da Identidade Visual, 1977.

BOMFIM, Gustavo Amarante; NAGEL, Klaus-Dieter; ROSSI, Lia M. Desenho industrial: proposta para reformulação do currículo mínimo. 1978. Dissertação (mestrado do Programa de Engenharia de Produção COPPE/UFRJ). Rio de Janeiro, 1978. 
CAMEIRA, Sandra Ribeiro. História e conceitos da identidade visual nas décadas de 1960 e 1970. In: BRAGA, Marcos da Costa (Org.); MOREIRA, Ricardo Santos (Org.). Histórias do design no Brasil. São Paulo: Annablume, 2012.

CHAVES, Norberto. La imagem corporativa - teoria y práctica de la identificación institucional. Barcelona: Editorial Gustavo Gilli, 2008.

COSTA, Joan. A imagem da marca. Um fenômeno social. Tradução. Osvaldo Antonio Rosiano. São Paulo: Rosari, 2011.

LÖBACH, Bernd. Design Industrial: bases para a configuração de produtos industriais. São Paulo: Edgard Blücher, 2001.

MARTINS, José Roberto. Branding: um manual para criar, gerenciar e avaliar marcas. São Paulo: Global Brands, 2006.

OLINS, Wally. Corporate Identity. Making business strategy visible through design. London: Thames \& Hudson, 1989.

PEREZ, Clotilde. Signos da marca. expressividade e sensorialidade. São Paulo: Pioneira Thomson Learning, 2004.

REZENDE, Marco Antonio Amaral. Identidade visual: conceitos e práticas. Revista Marketing Paulista, $\mathrm{n}$. 65, Março/79.

SEMPRINI, Andrea. A marca pós-moderna: poder e fragilidade da marca na sociedade contemporânea. Tradução de Elisabeth Leone. São Paulo: Estação das Letras, 2006.

STOLARSKI, André. A identidade visual toma corpo. In: MELO, Francisco Homem. O design gráfico brasileiro, anos 60. São Paulo: Cosac Naify, 2006.

WHEELER, Alina. Design de identidade de marca: um guia completo para a criação, construção e manutenção de marcas fortes. Porto Alegre: Bookman, 2008. 